ADLFI. Archéologie de la France -

Informations

une revue Gallia

Haute-Normandie | 2006

\title{
Harfleur - La Porte de Rouen
}

Bruno Duvernois

Édition électronique
URL : http://journals.openedition.org/adlfi/5258

ISSN : 2114-0502

Éditeur

Ministère de la Culture

Référence électronique

Bruno Duvernois, "Harfleur - La Porte de Rouen », ADLFI. Archéologie de la France - Informations [En ligne], Haute-Normandie, mis en ligne le 01 mars 2006, consulté le 14 novembre 2019. URL : http:// journals.openedition.org/adlfi/5258

Ce document a été généré automatiquement le 14 novembre 2019.

(c) Ministère de la Culture et de la Communication, CNRS 


\section{Harfleur - La Porte de Rouen}

\section{Bruno Duvernois}

\section{Identifiant de l'opération archéologique : 4244}

Date de l'opération : 2006 (EX)

Dans le cadre du projet de réhabilitation de l'entrée sud-est d'Harfleur, la municipalité a souhaité que soient organisées sur le site de la Porte de Rouen des recherches archéologiques et des chantiers d'études et de restauration du bâti, avec la participation de la population locale (Fig. $n^{\circ} 1$ : Plan de masse du bâti et des sondages).

2 La Porte de Rouen est un ensemble monumental édifié pendant la guerre de Cent Ans pour protéger la ville et l'arsenal royal des incursions anglaises. Seule porte conservée sur les trois que comptait la ville, elle présente deux monuments remarquables par leur état de conservation : la Porte aux Cerfs, édifiée entre 1391 et 1399 ; le boulevard en pierre qui a remplacé un édifice de terre et de bois construit par les Anglais après le siège de 1415.

Ce nouveau boulevard est une ceinture de maçonnerie se développant en demi-fer à cheval sur quarante mètres, flanquée de quatre tours, comprenant des casemates et des canonnières, aménagements mentionnés dans les comptes de travaux de construction et de réparation de l'administration royale française et anglaise conservés dans les archives.

Dans une première approche, des sondages programmés pour l'année 2006 avaient pour but, d'une part de mesurer le potentiel stratigraphique du site et, d'autre part, de vérifier l'état de conservation des vestiges enfouis.

5 S'appuyant sur le relevé topographique et la levée d'un plan de masse, l'étude s'est concentrée sur les vestiges du boulevard:

6 L'étude archéologique de la Porte aux Cerfs a été plus fructueuse. Mis à part l'extraction des remblais du fossé, semblable à celle réalisée à l'extérieur du boulevard, un sondage réalisé entre la courtine ouest et la clôture du site a révélé l'existence de structures de cheminement (dallage + empierrement de galets) associées à des niveaux d'occupation, et une stratigraphie qui montre la persistance de l'usage de l'endroit jusqu'à la fin du $\mathrm{XV}^{\mathrm{e}} \mathrm{s}$. et au début du XVI ${ }^{\mathrm{e}} \mathrm{s}$. 


\section{ANNEXES}

Fig. $\mathrm{n}^{\circ} 1$ : Plan de masse du bâti et des sondages

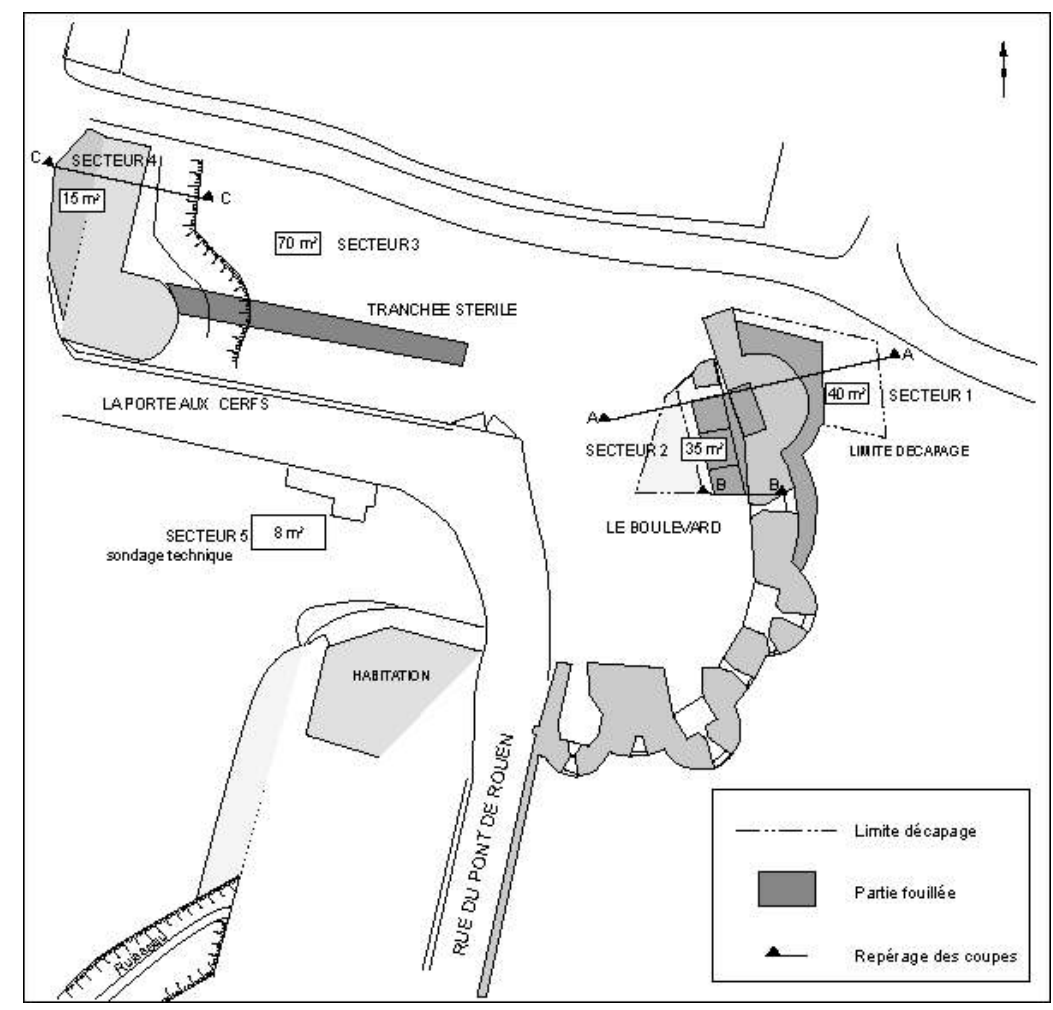

Auteur(s) : Duvernois, Bruno. Crédits : ADLFI (2006) 
Fig. $n^{\circ} 2$ : Vue générale des élévations conservées

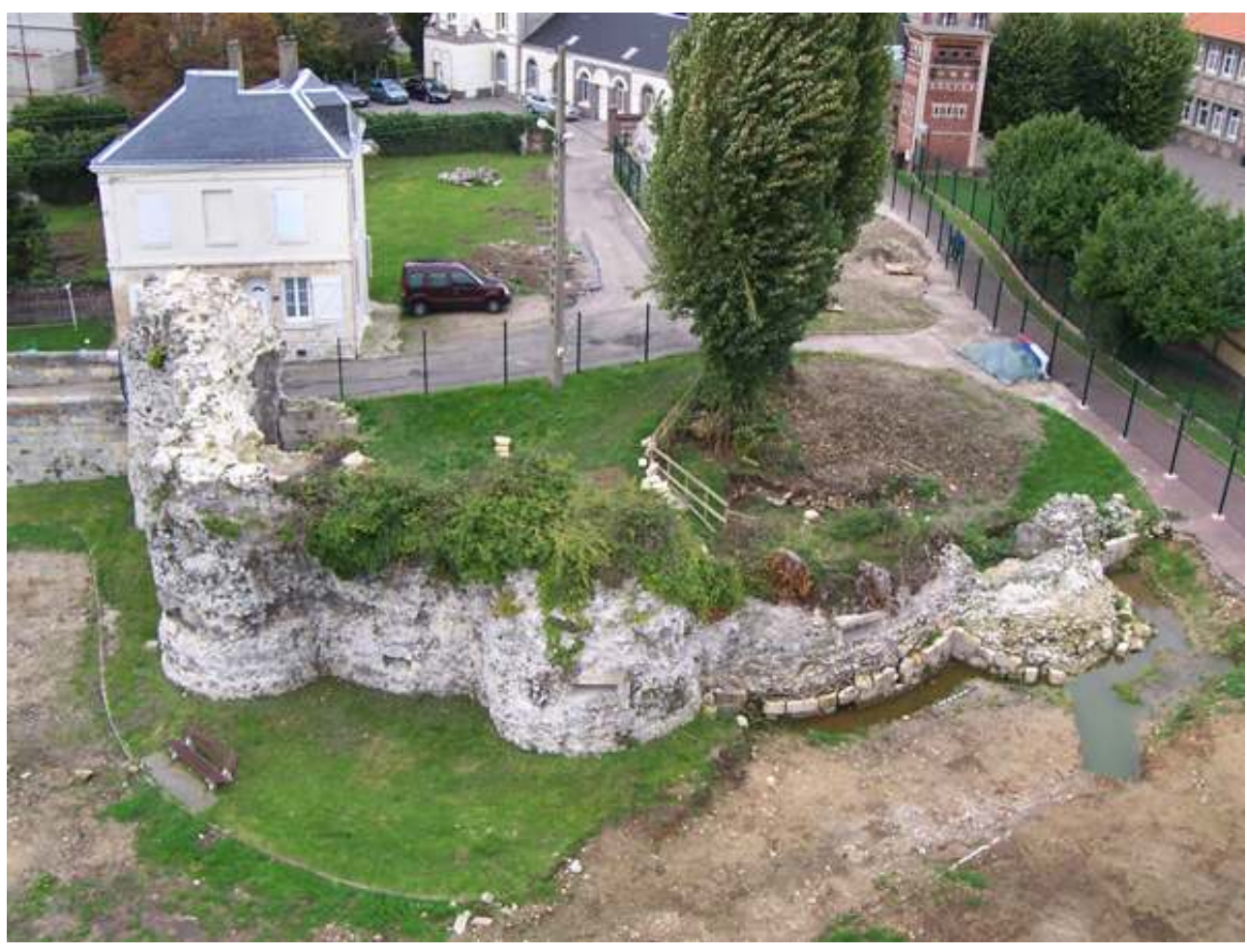

Auteur(s) : Duvernois, Bruno. Crédits : ADLFI (2006)

INDEX

Index géographique : Haute-Normandie, Seine-Maritime (76), Harfleur operation Expertise (EX)

Index chronologique : XVe siècle apr. J.-C., Moyen Âge*

\section{AUTEURS}

\section{BRUNO DUVERNOIS}

Collectivité territoriale 